\title{
Issue Unbundling via Citizens' Initiatives
}

\author{
By Timothy Besley and Stephen CoAte*
}

\begin{abstract}
The role of citizens' initiatives figures prominently in contemporary debates on constitutional change. It is widely believed that permitting initiatives should improve the congruence between citizen preferences and policy outcomes across the spectrum of issues on which initiatives may be placed. This paper investigates the theoretical basis for this view. It begins by identifying three basic reasons why electoral competition may not, by itself, be sufficient to ensure congruence on specific issues. Each reason relies critically on the fact that citizens have only one vote to cast for candidates who have responsibility for choosing a bundle of issues. It then shows how allowing initiatives permits the unbundling of specific issues which improves congruence when the three reasons apply. Important caveats to this logic are also presented.
\end{abstract}

While some form of commitment to majority rule is at the heart of every democratic system, the range of institutions used to make social decisions under this banner varies enormously. Most systems have in common the use of elected representatives to determine policy. Direct input from voters is, in general, limited. However, one important exception is the use in some political systems of citizens' initiatives - a form of direct democracy that permits citizens to place legislative proposals on the ballot (see Matsusaka 2005 for an introduction). If passed, an initiative binds the elected representatives and hence reduces policy maker discretion relative to a pure representative democracy. To place an initiative on the ballot, a citizen (or group of citizens) must present a petition signed by some required fraction of the electorate. Some form of initiative is currently permitted in twenty-four of the U.S. states. ${ }^{1}$

It is widely believed that permitting citizens' initiatives improves congruence between citizens' preferences and policy outcomes across the spectrum of issues on which initiatives may be brought. This premise has been traditionally accepted by their proponents and critics alike, with the main debate focusing on the desirability of allowing voters' opinions a larger weight. ${ }^{2}$ It also receives strong empirical backing. Gerber 1999 finds that policy outcomes on the death penalty and abortion regulation are closer to public opinion in states that permit citizens' initiatives. This is 
so, even though initiatives have not been brought on these specific issues. Matsusaka 2004 finds that U.S. states which permit citizens' initiatives also have lower levels of public spending, greater decentralization of spending decisions to the local level, and greater reliance on user fees rather than taxes (see also Matsusaka 1995). He then presents opinion poll data suggesting that the majority of voters approve of these policy changes attributed to the initiative. Matsusaka 2007, in a comprehensive cross-state study of ten high profile issues, also finds greater congruence between policy choices and public opinion in states that permit voter initiatives.

This paper investigates the theoretical basis for the view that initiatives make policy more congruent with public opinion. The underlying theoretical framework is the model of electoral competition with a two-dimensional policy space employed in Besley and Coate 2003a and 2003b. The model features two political parties, comprised of policy-motivated citizens, that compete by selecting citizen-candidates. In this framework, the paper studies the implications for policy outcomes of allowing citizens to place initiatives in one of the two policy dimensions. In particular, it analyzes how initiatives affect the congruence of policy outcomes and citizen preferences in that dimension.

The analysis isolates three reasons why the forces of electoral competition may not, by themselves, be sufficient to produce congruence between citizen preferences and policy outcomes on both issues. These are (i) when there are divergences between elite and popular opinion on an issue and that issue is not salient in the election; (ii) when there is a group of voters who hold a minority view on an issue but vote as single issue voters; and (iii) when a minority view is supported by an organized interest group that provides campaign contributions to candidates sharing its position. The logic of each of these arguments rests on issue bundling - the fact that citizens have only one vote to cast for a representative who must decide on a bundle of issues. This echoes a familiar theme in political science. ${ }^{3}$

These arguments provide some theoretical underpinning for the large literature that investigates the relationship between public opinion and policy outcomes. This literature shows that, while there is substantial congruence between public opinion and policy, specific issues exhibit divergence. ${ }^{4}$ For example, Weissberg's case studies of eleven policy issues revealed three cases - gun control, religion in public schools, and foreign aid - in which policy differed starkly from majoritarian preferences (Weissberg 1976). Matsusaka's 2007 study finds the states chose the majority preferred policy outcome only 59 percent of the time. 
The paper shows next how allowing citizens to place initiatives on one of the issues permits it to be unbundled from the other. This can improve congruence between policy and public opinion when the two are initially divergent in any of the cases identified above. Initiatives may work directly by removing discretion on the issue from the elected representative or indirectly by changing the policy stances of the candidates that the parties select. The analysis also points out that if conditions are such that electoral competition delivers a congruent outcome, then permitting initiatives can worsen congruence. Thus, the analysis isolates the situations in which initiatives will have the greatest impact on congruence.

A number of other papers have previously sought to understand theoretically why allowing initiatives on an issue might improve congruence (for example, Denzau, Mackay and Weaver 1981 and Gerber 1996). ${ }^{5}$ However, these papers start from the assumption that elected representatives do not hold congruent views on the issue in question. They therefore skirt the question of why electoral competition does not deliver representatives with congruent preferences. Our contribution is to understand how and why initiatives matter when representatives compete for the right to control policy.

In the initiative literature, two alternative perspectives on why initiatives may improve congruence are discussed. If special interests bribe policy-makers to support legislation after they have been elected, then elections have limited ability to combat interest group influence (see, for example, Besley and Coate 2001). By allowing citizens to bypass the legislature, initiatives can facilitate anti-special interest legislation. This idea seems to have been important when initiatives were introduced in the U.S. at the turn of the twentieth century (see, for example, Magleby 1984). The second idea is that initiatives may counteract the effects of log-rolling in legislatures (Matsusaka 1995). A policy that benefits citizens in a minority of districts, may be passed if representatives in the minority districts purchase the votes of representatives in the majority districts by promising to vote for bills they favor. An initiative allows citizens to strike down such legislation. Our issue unbundling perspective is complementary to these. Indeed, the second idea can be conceptualized as initiatives being used to unbundle legislative log-rolls (Matsusaka 2005).

\section{THE MODEL}

The model chosen is deliberately simple. One key feature is the choice of a discrete policy issue on which initiatives can be held. The notion of congruence between policy outcomes and 
public opinion is easy to define in this case. Later we discuss how the insights might be extended to more general settings.

\section{Government policies}

A community must decide on two issues: public spending and a regulation. The level of public spending is denoted by $g$ and the regulation by $r \in\{0,1\}$. The regulation can be interpreted broadly, for example as an economic issue like affirmative action or a non-economic issue like gun control. If the regulation is in place then $r=1$, otherwise $r=0$.

Citizens' preferences differ over the two issues. On public spending, there are two preference types: left-wing and right-wing. A citizen of spending preference type $k \in\{l, r\}$ obtains a net benefit $b(g ; k)$ from public spending level $g$. The function $b(\cdot ; k)$ is single-peaked with a unique maximum $g^{*}(k)>0$. Left-wingers have a higher demand for public spending, so that $g^{*}(l)>$ $g^{*}(r)$. There are also two preference types with respect to the regulation: anti-regulation and pro-regulation. A citizen with regulatory attitude $t \in\{a, p\}$ obtains a net benefit $\theta_{t}$ when the regulation is enacted, where $\theta_{a}<0<\theta_{p}$. Let $r^{*}(t)$ denote the optimal regulatory outcome from the perspective of citizens with regulatory attitude $t$.

The fraction of citizens of type $(k, t)$ is denoted by $\gamma_{t}^{k}$. We let $\gamma^{k}$ denote the fraction of the population with public spending preference $k$ and $\gamma_{t}$ the fraction with regulatory attitude $t$. We assume throughout that anti-regulation citizens are in a minority, i.e., $\gamma_{a}<\min \left\{\gamma^{l}, \gamma^{r}\right\}$.

\section{Policy determination}

Policy-making is delegated to an elected representative. Representatives are citizens and are characterized by their types $(k, t)$. No ex-ante policy commitments are possible, so that a type $(k, t)$ representative chooses a public good level $g^{*}(k)$ and makes regulatory decision $r^{*}(t)$.

Candidates in the election are put forward by two political parties, denoted $A$ and $B$. Each party is comprised of member citizens bound together by their views on public spending. Thus, all members of Party $A$ are left-wingers and all members of Party $B$ are right-wingers. Parties contain a mixture of pro and anti-regulation citizens. ${ }^{6}$ Let $t_{J}^{*}$ denote the regulatory attitude of the majority of Party J's members. Party members are a subset of the total voting population and hence may have views which are not representative of the citizens at large. Thus, it is not necessarily the case that $t_{J}^{*}=p$.

Each party selects the candidate a majority of its members prefers. Thus the majority members of each party are a kind of political elite that control access to political office. Since the members 
of each party share the same public spending preferences, there are effectively only two types of citizens in each party: those who favor the regulation and those who oppose it. The preferences of the largest of these two groups therefore determine the majority preferred candidate for the party.

We do not require that each party select a candidate from the ranks of its membership. Thus, Party $A(B)$ could draft a right-winger (left-winger) to run as its candidate if its majority members prefer such a candidate. While in the equilibria that we will study parties do run candidates who share their members' spending preferences, we do not want any of the conclusions to be driven by the assumption that parties must pick such candidates. Indeed, since a candidate implements his preferred policy outcome if elected, there is no reason for an individual to turn down the opportunity to run as a party's candidate even when he does not share the core beliefs of party members.

There are two types of voters. A fraction $\mu$ are rational voters who anticipate the policy outcomes each candidate would deliver and vote for the candidate whose election would produce their highest policy payoff. Thus, a rational voter of type $(k, t)$ faced with candidates of types $\left(k_{A}, t_{A}\right)$ and $\left(k_{B}, t_{B}\right)$ will vote for Party $A$ 's candidate if $b\left(g^{*}\left(k_{A}\right), k\right)+\theta_{t} r^{*}\left(t_{A}\right)$ exceeds $b\left(g^{*}\left(k_{B}\right), k\right)+\theta_{t} r^{*}\left(t_{B}\right)$. Rational voters indifferent between two candidates abstain.

Following Baron 1994 and Grossman and Helpman 1996, the remaining fraction are noise voters. ${ }^{7} \mathrm{~A}$ fraction $\eta$ of these vote for Party $A$ 's candidate, where $\eta$ is the realization of a random variable with support $[0,1]$ and cumulative distribution function $H(\eta)$. The idea is that noise voters respond to non-policy relevant features of candidates such as their looks, sense of humor, etc. We assume that $H$ is increasing and symmetric so that for all $\eta, H(\eta)=1-H(1-\eta)$. This implies that noise voters are unbiased in the sense that the probability that a fraction less than $\eta$ vote for Party $A$ 's candidate equals the probability that a fraction less than $\eta$ vote for Party $B$ 's candidate.

Noise voters make election outcomes probabilistic. To illustrate, consider an election in which the difference between the fraction of citizens obtaining a higher utility from the policy choices generated by Party $A$ 's candidate and the fraction obtaining a higher utility from Party $B$ 's candidate is $\omega$. Since $\mu$ is the fraction of rational voters and $\eta$ the fraction of noise voters who vote for Party A's candidate, Party A's candidate will win if $\mu \omega+(1-\mu) \eta$ exceeds $(1-\mu)(1-\eta)$ or, equivalently, if $\eta$ exceeds $\frac{-\mu \omega}{2(1-\mu)}+\frac{1}{2}$. The probability that Party A's candidate will win is thus 
$\psi(\omega)$ where

$$
\psi(\omega)=\left\{\begin{array}{c}
0 \text { if } \omega<\frac{-(1-\mu)}{\mu} \\
1-H\left(\frac{-\mu \omega}{2(1-\mu)}+\frac{1}{2}\right) \text { if } \omega \in\left[\frac{-(1-\mu)}{\mu}, \frac{(1-\mu)}{\mu}\right] . \\
1 \text { if } \omega>\frac{(1-\mu)}{\mu}
\end{array}\right.
$$

We assume throughout that $\left|\gamma^{l}-\gamma^{r}\right|$ is less than $(1-\mu) / \mu$, which puts an upper bound on the number of rational voters. This assumption implies that $\psi\left(\gamma^{l}-\gamma^{r}\right) \in(0,1)$.

Party members know the election probabilities associated with different candidate pairs and take them into account when selecting candidates. An equilibrium is a pair of candidates - one for each party - such that each party's majority members is happy with its choice. More formally, a pair of candidates $\left(k_{A}, t_{A}\right)$ and $\left(k_{B}, t_{B}\right)$ is an equilibrium if type $\left(l, t_{A}^{*}\right)$ citizens prefer a type $\left(k_{A}, t_{A}\right)$ candidate to any other type of candidate given that Party $B$ is running a type $\left(k_{B}, t_{B}\right)$ candidate and, conversely, type $\left(r, t_{B}^{*}\right)$ citizens prefer a type $\left(k_{B}, t_{B}\right)$ candidate to any other type of candidate given that Party $A$ is running a type $\left(k_{A}, t_{A}\right)$ candidate. Any equilibrium gives rise to a probability distribution over outcomes: the policy outcome will be that associated with Party $J$ 's candidate with a probability equal to the chance that Party $J$ 's candidate wins.

\section{SOURCES OF NON-CONGRUENCE UNDER ELECTORAL COMPETITION}

This section develops three arguments as to why the forces of electoral competition may not produce congruence on the regulatory issue. In the first example, regulation is not a politically salient issue and the majority members of one or both parties are anti-regulation. In the second, regulation is a salient issue for only those voters who oppose it. In the third, regulation is not salient for any group of voters, but an anti-regulation interest group provides contributions to candidates favoring its position. As will be repeatedly emphasized, each argument relies critically on the fact that the elected representative is responsible for choosing both public spending and regulation.

\section{Issue non-salience and party preferences}

Suppose that public spending is more important to citizens than is regulation in the following precise sense - for each type of citizen $(k, t)$, the gain from achieving their preferred level of public spending, given by $\Delta b(k)=b\left(g^{*}(k), k\right)-b\left(g^{*}(-k), k\right)$, exceeds the gain from achieving their preferred regulatory policy, given by $\left|\theta_{t}\right| .^{8}$ Thus, disagreement over public spending is sharper 
than that over regulatory policy. Under this assumption, if the two parties select candidates with different public spending preferences, all rational voters prefer the candidate who shares their public good preferences irrespective of his stance on regulation. Regulation is not, therefore, a politically salient issue.

Under this assumption, if Party $A$ selects a left-winger and Party $B$ a right-winger, there is no electoral gain to party members from selecting a candidate whose position on regulation differs from their ideal. Each party's candidate will therefore have the same attitude toward regulation as the party's majority members. Since rational voters vote according to the candidates' spending preferences, Party A's candidate will win with probability $\psi\left(\gamma^{l}-\gamma^{r}\right)$.

For this to be an equilibrium, party members must prefer to select candidates who reflect their views on public spending. Neither group must want to compromise in the public spending dimension. It is clear that a party whose majority members are anti-regulation has no incentive to do so, since this compromise would reduce the probability that it achieves both of its policy objectives. However, since $\gamma_{p}$ exceeds $\gamma^{k}$ for $k \in\{l, r\}$, a party whose majority members are proregulation may wish to compromise in the spending dimension if the opposing party is selecting an anti-regulation candidate. For example, if $t_{A}^{*}=p, t_{B}^{*}=a$ and $\psi\left(\gamma^{l}-\gamma^{r}\right)$ is close to zero, then Party $A$ will choose a type $(R, p)$ candidate despite the fact that public spending is more important to its majority members than regulation. This possibility is ruled out by the following assumption:

Assumption 1: For $k \in\{L, R\}$

$\psi\left(\gamma^{k}-\gamma^{-k}\right) \Delta b(k)>\left[\psi\left(\gamma_{p}-\gamma_{a}\right)-\psi\left(\gamma^{k}-\gamma^{-k}\right)\right] \theta_{p}$.

The left-hand side is the expected loss in public spending benefits from a compromise on public spending, while the term on the right hand side is the expected gain in terms of regulatory outcome. The assumption implies that a compromise on public spending is not desirable for either party. It requires that the fractions $\gamma^{l}$ and $\gamma^{r}$ not be too far apart. ${ }^{9}$

Under Assumption 1, Party $A$ selecting a type $\left(l, t_{A}^{*}\right)$ candidate and Party $B$ a type $\left(r, t_{B}^{*}\right)$ candidate is the unique equilibrium. Thus, we have: ${ }^{10}$

Proposition 1. Suppose that regulation is not salient and that the majority members of at least one party are anti-regulation. Then, under Assumption 1, the regulatory outcome will not be congruent with the views of the majority with a probability of at least $\min \left\{\psi\left(\gamma^{l}-\gamma^{r}\right), 1-\psi\left(\gamma^{l}-\gamma^{r}\right)\right\}$. 
If the majority members of both parties are anti-regulation, the regulatory outcome will be noncongruent with probability one.

The key point is that since citizens have only one vote and there are multiple issues, there is some slack in the process that allows parties to indulge their policy preferences. Anti-regulation parties can run candidates with anti-regulation attitudes without paying an electoral penalty because regulatory policy is not salient for voters. The probability that these candidates win, reflects their popularity on the politically salient issues and regulatory policy does not reflect majority preferences.

This argument demonstrates how, with multiple issues, the fact that political elites disagree with a majority of citizens can translate into non-congruent policy outcomes. Moreover, there is no good reason to expect the preferences of such elites to conform with mass opinion. Examples abound. In the U.K., both major parties are against the death penalty, while an overwhelming majority of voters favor it. In the U.S., both major parties favor free trade and the Republican party is against the minimum wage.

\section{Single-issue voters}

Suppose now that the regulation is salient only for the minority of voters who oppose it, i.e., for each $k \in\{l, r\}, \theta_{p}<\Delta b(k)<\left|\theta_{a}\right|$. This means that anti-regulation voters will act as single issue voters, voting for whichever party has an anti-regulation candidate. A good example for the U.S. is gun control - while a majority of citizens favor stricter controls, the minority who oppose this do so with greater intensity of feeling (Schuman and Presser 1977-8). Other plausible examples are affirmative action and immigration restrictions. ${ }^{11}$

Even if its majority members are pro-regulation, a party may be willing to court the antiregulation voters by running an anti-regulation candidate. To see this, suppose that Party $A$ is selecting a left-winger and Party $B$ a right-winger who is pro-regulation. If Party $A$ selects an anti-regulation candidate it will attract the support of all the anti-regulation voters in Party $B$ 's base. This will raise the probability that its candidate will win and implement its preferred spending level. This gain will offset the reduced probability of its preferred regulatory outcome if spending is relatively more important. If, on the other hand, Party $B$ were running an antiregulation candidate then Party $A$ will lose the anti-regulation voters in its base unless it runs an anti-regulation candidate.

The argument relies crucially on the assumption that the parties offer candidates with differing 
public spending preferences. If this were not the case, then the only issue in the election would be regulation and the majority of votes would go to the pro-regulation candidate. Parties will offer candidates with differing public spending preferences when spending is sufficiently important relative to regulation that they would prefer a smaller probability of getting their preferred public spending outcome to a higher probability of getting their preferred regulatory outcome.

The following assumption embodies the precise conditions under which equilibrium involves both parties selecting candidates who share the public spending preferences of their members, but who are anti-regulation.

Assumption 2: For $k \in\{l, r\}$

(i) $\psi\left(\gamma^{k}-\gamma^{-k}\right) \Delta b(k)>\psi\left(\gamma_{p}-\gamma_{a}\right) \theta_{p}$,

(ii) $\left[\psi\left(\gamma^{k}-\gamma^{-k}\right)-\psi\left(\gamma_{p}^{k}-\left(\gamma_{a}^{k}+\gamma^{-k}\right)\right)\right] \Delta b(k)>\psi\left(\gamma_{p}^{k}-\left(\gamma_{a}^{k}+\gamma^{-k}\right)\right) \theta_{p}$,

and

(iii) $\left[\psi\left(\left(\gamma^{k}+\gamma_{a}^{-k}\right)-\gamma_{p}^{-k}\right)-\psi\left(\gamma^{k}-\gamma^{-k}\right)\right] \Delta b(k)>\psi\left(\left(\gamma^{k}+\gamma_{a}^{-k}\right)-\gamma_{p}^{-k}\right) \theta_{p}$.

Parts (i) and (ii) imply that both parties selecting anti-regulation candidates who share their public spending preferences is an equilibrium. Part (i) ensures that neither party has an incentive to put forward a pro-regulation candidate with the opposing party's public spending preferences. It requires that each party's lost chance of getting its preferred level of public spending is more costly than the benefits from the improved chance of getting its preferred regulatory outcome. Part (ii) ensures that neither party wishes to switch to a pro-regulation candidate if each is fielding an anti-regulation candidate. It requires that the electoral penalty stemming from the loss of each party's anti-regulation constituency is prohibitive. Part (iii) guarantees that both parties selecting anti-regulation candidates is the only equilibrium. It ensures that, when they are fielding candidates with different public spending preferences, both parties have an incentive to select an anti-regulation candidate if the other party were to field a pro-regulation candidate. It requires that the electoral gain associated with attracting the other party's anti-regulation constituency is large.

We now have:

Proposition 2. Suppose that the majority of each party's members are pro-regulation and that regulation is salient only for those who oppose it. Then, under Assumption 2, the regulatory outcome will not be congruent with the views of the majority with probability one. 
This gives a theoretical underpinning for the commonly expressed idea that intense minorities can have political influence over the issues that they care about. ${ }^{12}$ This kind of logic can explain the persistence of weak gun control, affirmative action, and lax immigration restrictions in the U.S. despite majority opinion. The multi-dimensionality of the policy space is critical to the story. First, the fact that there is an electoral gain from pandering to anti-regulation voters is because the pro-regulation voters are voting on other issues. Second, the fact that the parties are willing to pander is because of their desire to further their objectives in another policy dimension.

\section{Interest group influence}

To incorporate interest group influence as simply as possible, we assume that a group of citizens who oppose the regulation are organized as an interest group that makes contributions to the campaigns of anti-regulation candidates. These contributions are used to buy the votes of noise voters and enhance the election chances of the favored candidates. Contributions are given after the parties have selected candidates and are anticipated by party members when selecting candidates. An equilibrium now consists of (i) a function describing the interest group's optimal contribution to the candidates for any pair of candidate types, and (ii) a pair of candidate types that are preferred by the majority members of each party given the interest group's contribution behavior.

We begin by describing the mechanism by which campaign contributions buy votes. Consider an election in which the difference between the campaign expenditures of the two parties' candidates is $z$. If $z$ is positive, Party $A$ 's candidate is outspending B's and vice versa. Then the fraction of noise voters voting for Party $A$ 's candidate, $\eta$, is a random variable with support $[0,1]$ and cumulative distribution function $H(\eta ; z)$. The function $H$ is assumed to be twice continuously differentiable and to satisfy the conditions that for all $z, H(0 ; z)=0$ and $H_{\eta}(\eta ; z)>0$ for all $\eta$. In addition, for all $\eta \in(0,1)$ and $z, H_{z}(\eta ; z)<0$, implying that an increase in spending for $A$ 's candidate leads to a distribution of noise voters that first order stochastically dominates the

original distribution. To ensure that noise voters remain unbiased, we also restrict $H(\eta ; z)$ to be symmetric, so that for all $\eta$ and $z, H(\eta, z)=1-H(1-\eta,-z)$. This implies that the probability that Party A's candidate gets a fraction of noise voters less than $\eta$ when he out-spends Party $B$ 's candidate by an amount $z$ equals the probability that Party $B$ 's candidate gets a fraction of noise voters less than $\eta$ when he outspends Party $A$ 's candidate by the same amount. Finally, we assume that for all $\eta \in(0,1)$ and $z>0, H_{z z}(\eta ; z)>0$, implying diminishing returns to outspending an 
opponent.

Turning to the interest group, a fraction $\xi<1$ of those opposing the regulation belong to the interest group. This group seeks to maximize the objective function $\xi \gamma_{a} \theta_{a} r-x$ where $r$ denotes the regulatory outcome and $x$ denotes campaign contributions. To determine the interest group's contribution, consider an election in which the difference between the fraction of citizens obtaining a higher utility from Party $A$ 's candidate and the fraction obtaining a higher utility from Party $B$ 's candidate is $\omega$. If both candidates have the same regulatory stance, the interest group makes no campaign contribution. However, if Party $A$ 's candidate is anti-regulation and Party $B$ 's is pro, then the interest group may contribute to Party A's candidate. Generalizing the earlier analysis, let $\widehat{\psi}(\omega, z)$ be the probability that Party $A$ 's candidate wins when the difference between the two candidates' campaign expenditures is $z{ }^{13}$ Then the interest group contributes $x^{*}(\omega)$ to Party $A$ 's candidate, where

$$
x^{*}(\omega)=\arg \max \left\{\widehat{\psi}(\omega, x) \xi \gamma_{a}\left|\theta_{a}\right|-x: x \geq 0\right\} .
$$

If Party A's candidate is pro-regulation and Party $B$ 's is anti, the interest group contributes $x^{*}(-\omega)$ to Party $B$ 's candidate.

To illustrate how interest group influence leads to non-congruent policy outcomes, suppose that regulation is not salient and that a majority of each party's members are pro-regulation. Then, both parties may pander to the interest group by running an anti-regulation candidate to avoid giving the other party the electoral advantage of interest group support. Consider the situation of Party $A$, knowing that Party $B$ is planning to select a right-wing candidate who is anti-regulation. If Party $A$ selects a pro-regulation left-winger, the interest group will contribute to Party $B$ 's candidate. This could significantly reduce the probability $A$ 's candidate wins and is able to implement the party's preferred public spending plan. The logic is similar to that underlying the single issue voter case, except that money to buy votes rather than votes themselves are the motivating force.

The equivalent of Assumption 2 in terms of campaign contributions is:

Assumption 3: For $k \in\{l, r\}$

(i) $\psi\left(\gamma^{k}-\gamma^{-k}\right) \Delta b(k)>\widehat{\psi}\left(\gamma_{p}-\gamma_{a},-x^{*}\left(\gamma_{a}-\gamma_{p}\right)\right) \theta_{p}$,

(ii) $\left[\psi\left(\gamma^{k}-\gamma^{-k}\right)-\widehat{\psi}\left(\gamma^{k}-\gamma^{-k},-x^{*}\left(\gamma^{-k}-\gamma^{k}\right)\right)\right] \Delta b(k)>\widehat{\psi}\left(\gamma^{k}-\gamma^{-k},-x^{*}\left(\gamma^{-k}-\gamma^{k}\right)\right) \theta_{p}$,

and 
(iii) $\left[\widehat{\psi}\left(\gamma^{k}-\gamma^{-k}, x^{*}\left(\gamma^{k}-\gamma^{-k}\right)\right)-\psi\left(\gamma^{k}-\gamma^{-k}\right)\right] \Delta b(k)>\widehat{\psi}\left(\gamma^{k}-\gamma^{-k}, x^{*}\left(\gamma^{k}-\gamma^{-k}\right)\right) \theta_{p}$.

Under this assumption, equilibrium involves the two parties running anti-regulation candidates. Thus we have:

Proposition 3. Suppose that there is an anti-regulation interest group, the majority members of each party are pro-regulation, and that regulation is not salient. Then, under Assumption 3, the regulatory outcome will not be congruent with the views of the majority with probability one.

Thus the interest group guarantees that its position on the regulatory issue prevails. Moreover, it does so without actually paying any campaign contributions in equilibrium! The threat of supporting any candidate with pro-regulation views is sufficient. The multi-dimensionality of the policy space is once again critical to the story. First, the fact that there is an electoral gain from pandering to the interest group is because the pro-regulation voters are voting on other issues. Second, the fact that the parties are willing to pander is because of their desire to further their objectives in another policy dimension. The most natural examples for this explanation are regulations that harm business interests, such as gambling restrictions or regulations to clean up the entertainment industry. Favoring such regulations would be unlikely to win a candidate many votes, but might well encourage the affected industries to contribute to his opponent.

\section{Remarks}

We have emphasized the point that all three of these examples rest critically on the fact that elected representatives must choose both public spending and regulation. Another way to see this is to note that if regulation were the only issue, the policy outcome would be congruent with probability one if (i) the majority members of at least one party were pro-regulation and (ii) the fraction of rational voters is sufficiently high so that $\gamma_{p}-\gamma_{a}>(1-\mu) / \mu$. Condition (i) implies that at least one party would put forward a pro-regulation candidate and (ii) implies that a proregulation candidate would defeat an anti-regulation candidate with probability one if regulation were the only issue. However, the conditions of Propositions 1, 2 or 3 are all consistent with (i) and (ii) holding.

The assumption of policy-motivated parties is also crucial to these examples. In a model where parties select candidates to maximize their chance of winning, either both parties would pick a pro-regulation candidate of the majority preferred spending type or there is no equilibrium in pure strategies. ${ }^{14}$ It is not, however, critical that parties monopolize candidate selection. Allowing 
independent citizen-candidates to enter would not force the parties to select candidates with the majority view on regulation. ${ }^{15}$

As noted in the introduction, the three arguments developed here are useful for understanding the empirical literature on congruence between policy and preferences of citizens. They show that there are logically distinct explanations of non-congruence. Having this more precise theoretical underpinning will hopefully be useful in shaping future empirical studies.

\section{THE IMPACT OF CITIZENS' INITIATIVES}

We now develop the model to allow for the possibility of citizens' initiatives on the regulatory issue. To introduce initiatives formally, suppose that any citizen can place a proposal on the ballot regarding the regulation at a cost of $\delta$. There are two possible proposals: that the regulation be implemented and its converse. Citizens vote directly on proposals at the same time that they are voting for candidates. If there is a single proposal and it receives majority support, it is implemented. Otherwise, the regulatory decision is left to the elected representative. Thus, the citizens' vote is binding only if it is in favor of the proposal. If both proposals are on the ballot, and one or more proposals gets a majority vote, then the proposal receiving the most support is implemented.

Citizens decide whether or not to introduce an initiative after the parties have selected their candidates. Thus, they know the likely regulatory outcome if no initiatives are introduced. Moreover, party members can anticipate how their selection of candidates will impact the likelihood of initiatives being offered.

We assume that the voting decisions over initiatives are governed by the same process as voting over candidates. Thus, a fraction $\mu$ are rational and vote for an initiative if they favor the outcome it prescribes and against it otherwise. The remainder are noise voters. If there is a single initiative the fraction voting in favor is a random variable with support $[0,1]$ and cumulative distribution function $H(\eta ; z)$ where $z$ is the difference in spending for and against the initiative. If both proposals are on the ballot, we require noise voters to vote in favor of one and against the other thereby disallowing voting for or against two conflicting proposals. This rules out the possibility of two conflicting proposals receiving majority support. Thus, the fraction voting in favor of the pro-regulation initiative and against the anti-regulation initiative is a random variable with support $[0,1]$ and cumulative distribution function $H(\eta ; z)$ where $z$ is the difference in spending 
in support of the two initiatives. These assumptions imply that votes for initiatives can be bought in exactly the same way as votes for candidates.

The timing of the political process is as follows. First, parties select their candidates. Next, citizens decide whether or not to put initiatives on the ballot. Then, if active, the interest group chooses how much to contribute to the candidates and/or the initiative campaigns. Finally, voters vote. To avoid a tedious investment in notation, we will not provide a detailed model of the game in which citizens decide whether to introduce initiatives. We will simply require that initiative proposals be consistent with the pure strategy equilibria of a game in which each citizen, having observed the candidates put forward, chooses whether or not to place an initiative. ${ }^{16}$ For most of the analysis, we will assume that $\delta$ (the cost of placing an initiative) is very small. The collective action problems arising from the large costs associated with placing an initiative will be discussed in the next section.

An equilibrium now consists of three things: (i) a function describing the interest group's optimal contributions to each Party's candidate and/or the initiative campaign for any candidate types and initiative decision, (ii) a function describing, for any given candidate pairs, the probabilities of each of the different ballot initiative possibilities; i.e., both initiatives are proposed, only the pro-regulation initiative is proposed, etc., and (iii) a pair of candidate types that are preferred by the majority members of each party given the anticipated behavior of those proposing initiatives and interest group contributions.

We now have the following result.

Proposition 4. Suppose that the constitution permits citizens' initiatives on the regulatory issue. Then, for sufficiently small $\delta$, any equilibrium produces the majority-preferred regulatory outcome with probability $\widehat{\psi}\left(\gamma_{p}-\gamma_{a},-x^{*}\left(\gamma_{a}-\gamma_{p}\right)\right)$ and the non-majority-preferred outcome with probability $1-\widehat{\psi}\left(\gamma_{p}-\gamma_{a},-x^{*}\left(\gamma_{a}-\gamma_{p}\right)\right)$.

This tells us that, when the costs of placing an initiative are small, any equilibrium must produce the same probability distribution over the regulatory policy outcome. If the fraction of rational voters is sufficiently high that $\gamma_{p}-\gamma_{a} \geq(1-\mu) / \mu$, this probability distribution selects the majority-preferred regulatory outcome with probability one (since $\widehat{\psi}\left(\gamma_{p}-\gamma_{a},-x^{*}\left(\gamma_{a}-\gamma_{p}\right)\right)=1$ ). If $\gamma_{p}-\gamma_{a}<(1-\mu) / \mu$, there is still a positive probability that a non-congruent regulatory outcome will arise. In addition, the power of the interest group is not eliminated as its activities reduce 
the probability that the regulation is introduced (if there were no interest group, $x^{*}=0$ and the probability of the non-congruent outcome is just $\left.1-\psi\left(\gamma_{p}-\gamma_{a}\right)\right)$. Even so, the regulatory outcome reflects only the citizens' preferences over regulation and the probability distribution is that which would arise if the regulatory policy issue were unbundled; i.e., decided on separately via a referendum. Hence, the influence of citizens' preferences over the other issues play no role in determining the policy outcome.

The proposition does not appeal to any special assumptions and hence applies to all the situations described in Propositions 1, 2 and 3. Thus, we have:

Corollary Suppose that the conditions of Propositions 1, 2 or 3 hold. Then, for sufficiently small $\delta$, allowing citizens' initiatives on the regulatory issue increases the likelihood that the regulatory policy outcome will be congruent with the views of the majority.

Thus, combining Propositions 1-4 yields a set of conditions under which the belief that permitting citizens' initiatives should improve congruence is correct.

It is nonetheless important to note that while there are conditions under which initiatives improve congruence, this is not necessarily the case. If regulatory policy would favor a majority of citizens under electoral competition and there is enough noise voting so that $\gamma_{p}-\gamma_{a}<(1-\mu) / \mu$, then permitting citizens' initiatives can actually increase the chances of an outcome that diverges from what a majority wants. Suppose, for example, that the issue is not salient and that the majority of members of both parties are pro-regulation. Then, the unique equilibrium without initiatives is that Party $A$ selects a candidate of type $(l, p)$ and Party $B$ selects a candidate of type $(r, p)$. The regulation would be introduced with probability one with no initiatives, while Proposition 4 implies that it would be introduced with probability $\psi\left(\gamma_{p}-\gamma_{a}\right)$ with initiatives. Thus, when there are enough noise voters, our argument does not rule out the possibility that allowing initiatives will worsen congruence. Rather, it shows that permitting initiatives will produce the same outcome as would arise from a direct vote on the issue. With noise voters, this does not always imply improving congruence. This argument applies with even greater force when there is an interest group that can buy the support of noise voters.

To understand the logic underlying Proposition 4, note first that the probability distribution described in the proposition would arise if both pro and anti-regulation initiatives were proposed. Under the assumption that noise voters vote in favor of one or the other initiative, then one 
initiative must receive majority support and this will decide the outcome. The regulatory issue is, in effect, removed from the control of the winning candidate. The interest group (if it exists) will devote $x^{*}\left(\gamma_{a}-\gamma_{p}\right)$ to supporting the anti-regulation initiative. Thus, the probability that the pro-regulation initiative will win is $\widehat{\psi}\left(\gamma_{p}-\gamma_{a},-x^{*}\left(\gamma_{a}-\gamma_{p}\right)\right)$. It follows that, if an equilibrium generated a probability distribution over the regulatory policy different from this, one or both of the initiatives would not be proposed. The proof of the proposition shows that, for sufficiently small $\delta$, it is not possible to have one or both initiatives not being proposed and have a probability distribution different from that described in the proposition.

Proposition 4 tells us that any equilibrium must produce the same probability distribution over regulatory policy outcomes. However, it leaves open the question of whether an equilibrium exists. Our next result resolves this question.

Proposition 5. Suppose that the constitution permits citizens' initiatives on the regulatory issue. Then, for sufficiently small $\delta$, there exists an equilibrium in which Party A selects a type $(l, p)$ candidate, Party $B$ selects a type $(r, p)$ candidate and the anti-regulation initiative is proposed if and only if $\gamma_{p}-\gamma_{a}<(1-\mu) / \mu$.

In this equilibrium, both parties select candidates who agree with a majority independently of the preferences of their members. Party members realize that to select an anti-regulation candidate would be futile. It would simply trigger a pro-regulation initiative that would take the issue out of the hands of the elected representative.

Two points about this equilibrium are worth noting. First, when $\gamma_{p}-\gamma_{a} \geq(1-\mu) / \mu$, the ability to propose initiatives affects the regulatory policy choice even though no initiative is actually proposed. This is consonant with the arguments of Gerber 1996 and 1999, who sees the threat of initiatives as important in shaping policy outcomes. Second, when $\gamma_{p}-\gamma_{a}<(1-\mu) / \mu$ only the anti-regulation initiative is proposed. Thus, the fact that we observe proposals that disagree with majority opinion and/or a majority of initiatives failing (see Magleby 1994), does not imply that initiatives are not serving the role of increasing congruence with majority opinion.

\section{DISCUSSION}

We have used an extremely simple model to understand how and why initiatives might improve congruence on the issues on which they may be placed. There are only two policy issues and two preference types for each issue. Moreover, the issue on which initiatives may be placed is a discrete 
issue. These assumptions certainly keep the analysis tractable and transparent, but does the logic of the argument depend upon them?

Even to pose the question: "Will allowing citizens' initiatives improve the congruence between citizen preferences and policy outcomes across the spectrum of issues on which initiatives may be placed?" requires a certain amount of structure on the policy space and citizens' preferences. This is necessary for the notion of "improved congruence" to have clear meaning. From a common sense perspective, the latter means moving outcomes on an issue closer to what the majority of citizens want. However, "what the majority of citizens want" may not itself be well-defined. Even when it is, it may depend on the levels of other policy issues. The latter means that improvements in congruence might arise even without any changes in the level of the policy in question!

Sufficient conditions for the question to be well-posed are that citizens' preferences are separable across issues and single-peaked over issues. Under these conditions, a majority preferred level of each policy exists and is independent of the levels of all other policies. Improving the congruence between citizen preferences and policy outcomes on an issue would mean moving closer to the majority preferred level of that particular policy. Such improvements in congruence could, in principle, be detected empirically through survey data. ${ }^{17}$ While such assumptions are undoubtedly strong, they are fairly standard in formal political science and seem implicit in the empirical literature on congruence, even though they are not stated explicitly.

Generalizing the paper's arguments to the case of a richer space of citizen types with separable and single-peaked preferences over multiple issues would undoubtedly by challenging. Existence of an equilibrium candidate pair selected by parties from the richer type space would be non-trivial. Nonetheless, it is clear that, if an equilibrium exists without initiatives it must involve parties choosing different candidate types. This suggests that there will be conditions under which specific issues will be salient for a negligible fraction of voters or only for those voters who feel strongly about an issue. The logic underlying the three earlier arguments then seems likely to apply. We are also optimistic that the logic of unbundling underlying Proposition 4 would continue to have some force. However, to make progress would require some understanding of what proposals citizens would make in a world in which initiatives could be placed for a continuous policy variable. This is a non-trivial theoretical problem.

Proposition 4 is valid only as $\delta$ goes to zero. Yet, even where constitutions permit citizens' initiatives, there are restrictive provisions for placing an initiative on the agenda. This makes $\delta$ 
very large in practice, beyond the reach of all but the most affluent of citizens. This means that collective action will typically be required to place an initiative. Outside of a perfect Coasian world, therefore, initiatives may not be proposed even if there is a group of citizens for whom the aggregate expected benefits exceed the cost. ${ }^{18}$ This will tend to dampen the disciplining role of initiatives.

This point applies with greater force in cases where it is those who hold the minority view who have greater access to the use of initiatives. ${ }^{19}$ For example, if only the interest group is organized enough to raise the cost $\delta$ and if $(1-\mu) / \mu>\gamma_{p}-\gamma_{a}$, permitting initiatives can (but will not necessarily) increase the likelihood that the interest group gets its preferred outcome.

Even ignoring these difficulties of interest group capture, it is important to note that our analysis does not imply a normative case for permitting citizens' initiatives, at least if we use standard economic criteria. Traditional welfare economics provides us no reason to believe that improving congruence on specific issues is socially desirable. Indeed, in the case of intense minorities discussed earlier, it may well be a bad thing from a utilitarian perspective. If there is a normative case for initiatives, it must stem from the non-welfarist belief that, in a democracy, it is socially undesirable for outcomes on specific issues to stray too far from what the majority wants. Initiatives then provide a useful supplement to representative democracy to rein it in when necessary. ${ }^{20}$

\section{CONCLUSION}

A considerable body of evidence suggests limited congruence between policy outcomes and public opinion on some policy issues. It is widely believed that permitting citizens' initiatives should improve congruence across the spectrum of issues on which initiatives may be placed. Available empirical evidence is supportive of this belief. This paper has provided one theoretical explanation of why this might be the case. It has done so by analyzing a model in which electoral competition and initiatives work in tandem.

While stylized, the analysis demonstrates the importance of issue unbundling to the way in which initiatives function. In candidate elections, voters who share a majority view on an issue may select who to vote for on the basis of other more salient issues. Thus their preferences play no role in the determination of policy on that issue. When an initiative is proposed, voting for a candidate on a salient issue no longer precludes an expression of preference on the issue in 
question. Thus the preferences of all the citizens on the issue are reflected in policy determination. Furthermore, initiatives do not need to be proposed for their impact to be felt - the threat of an initiative can change parties' incentives to select candidates. In this way, allowing initiatives forces greater congruence between policy outcomes and popular opinion on the issues on which they may be placed.

We have focused most of the analysis on finding conditions under which permitting citizens' initiatives improves congruence. However, we have also pointed out that when there are a large fraction of noise voters, initiatives can sometimes lead to greater divergence between public opinion and policy. This possibility is reinforced when there are interest groups with non-congruent views that buy the support of noise voters, particularly when such groups are differentially able to bear the costs of placing initiatives. Thus, the analysis yields a two-handed appreciation of initiatives, providing a vehicle to make the claims of recent critics precise.

The analysis suggests a sharper focus for empirical research seeking to identify the impact of initiatives on congruence. In particular, it suggests that we should expect the impact of initiatives on congruence to be greater for (i) non-salient issues for which either political elites have different preferences than the masses or rich interest groups back the minority position and (ii) issues that are salient only for those who hold the minority view. Testing these ideas provides an interesting agenda for future empirical work. 


\section{References}

Baron, David. 1994. "Electoral Competition with Informed and Uniformed Voters." American Political Science Review 88: 33-47.

Besley, Timothy and Stephen Coate. 2001. "Lobbying and Welfare in a Representative Democracy." Review of Economic Studies 68: 67-82.

Besley, Timothy and Stephen Coate. 2003a. "Elected versus Appointed Regulators: Theory and Evidence." Journal of the European Economic Association 1: 1176-1205.

Besley, Timothy and Stephen Coate. 2003b. "On the Public Choice Critique of Welfare Economics." Public Choice 114: 253-273.

Broder, David S. 2000. Democracy Derailed: Initiative Campaigns and the Power of Money. New York: Harcourt Inc.

Cronin, Thomas E. 1989. Direct Democracy: The Politics of Initiative, Referendum, and Recall. Cambridge, MA: Harvard University Press.

Denzau, Arthur T., Robert J. Mackay and Carolyn Weaver. 1981. "On the InitiativeReferendum Option and the Control of Monopoly Government." In Tax and Expenditure Limitations, eds. Helen F. Ladd and T. Nicolaus Tideman. Washington DC: The Urban Institute.

Dixit, Avinash, and John Londregan. 1996. "The Determinants of Success of Special Interests in Redistributive Politics." Journal of Politics LVIII: 1132-1155.

Gerber, Elisabeth. 1996. "Legislative Response to Threat of Popular Initiatives." American Journal of Political Science 40: 99-128.

Gerber, Elisabeth. 1999. The Populist Paradox: Interest Group Influence and the Promise of Direct Legislation. Princeton NJ: Princeton University Press.

Grossman, Gene and Elhanan Helpman. 1996. "Electoral Competition and Special Interest Politics." Review of Economic Studies 63: 265-286.

Herrera, Cheryl Lin, Richard Herrera and Eric R.A.N. Smith. 1992. "Public Opinion and Congressional Representation." Public Opinion Quarterly 56: 185-205.

Lindbeck, Assar and Jorgen Weibull. 1987. "Balanced-budget Redistribution as the Outcome of Political Competition." Public Choice 52: 272-297.

Magleby, David B. 1984. Direct Legislation: Voting on Ballot Propositions in the United States. Baltimore: The Johns Hopkins University Press.

Magleby, David B. 1994. "Direct Legislation in the American States," in Referendums Around the World: The Growing Use of Direct Democracy, eds. David Butler and Austin Ranney. Washington DC: AEI Press.

Matsusaka, John G. 1995. "Fiscal Effects of Voter Initiative: Evidence from the Last 30 Years." Journal of Political Economy 103: 587-623.

Matsusaka, John G. 2004. For the Many or the Few: The Initiative, Public Policy, and American Democracy. Chicago: University of Chicago Press. 
Matsusaka, John G. 2005. "Direct Democracy Works." Journal of Economic Perspectives 19: $185-206$.

Matsusaka, John G. 2007. "Popular Control of Public Policy." Working paper: University of Southern California.

Matsusaka, John G. and Nolan M. McCarty. 2001. "Political Resource Allocation: Benefits and Costs of Voter Initiatives." Journal of Law, Economics, and Organization 17: 413-448.

Miller, Warren E. and Donald E. Stokes. 1963. "Constituency Influence in Congress." American Political Science Review 57: 45-56.

Monroe, Alan D. 1979. "Consistency between Public Preferences and National Policy Decisions." American Politics Quarterly 7: 3-19.

Monroe, Alan D. 1983. "American Party Platforms and Public Opinion." American Journal of Political Science 27: 27-42.

Schuman, Howard and Stanley Presser. 1977-8. "Attitude Measurement and the Gun Control Paradox." Public Opinion Quarterly 41: 427-438.

Weissberg, Robert. 1976. Pubic Opinion and Popular Government. Prentice Hall: Englewood Cliffs, NJ.

Weissberg, Robert. 1978. "Collective vs. Dyadic Representation in Congress." American Political Science Review 72: 535-47. 


\section{Footnotes}

* Besley: Department of Economics, London School of Economics, London WC2A 2AE, U.K. (e-mail: t.besley@lse.ac.uk); Coate: Department of Economics, Cornell University, Ithaca, NY 14853 (e-mail: sc163@cornell.edu). This is a revision of a paper that first appeared in 2000 as NBER Working Paper \#8036. We thank the editors, the referees, and numerous seminar audiences for helpful comments. We are also indebted to John Matsusaka for a number of useful discussions.

1. Statutory initiatives in the U.S. states require between $2 \%$ and $15 \%$ of the voting population to sign a petition before an initiative can be placed. Initiatives are also permitted in many U.S. cities. As reported by Matsusaka 2004, over 70\% of the U.S. population lives in either a state or a city in which initiatives are permitted.

2. The traditional criticisms of initiatives are that they will be used by majorities to exert their will over minorities and that voters are insufficiently informed to decide on complex issues (see, for example, Cronin 1989). More recently, critics have argued that initiatives have become a tool for special interests with money having undue influence in initiative campaigns (see, for example, Broder 2000).

3. It is commonplace to observe that the fact that citizens have only one vote to cast for candidates who have stances on multiple issues limits the ability of elections to ensure congruence on all issues.

4. The literature tackles the problem of investigating congruence in a number of different ways. One approach is to look directly at the relationship between policy outcomes and citizens' preferences for specific policy issues (for example, Weissberg 1976, Monroe 1979 and Matsusaka 2007). Another approach explores the relationship between citizens' preferences and the voting behavior and/or policy preferences of their representatives (for example, Miller and Stokes 1963 and Herrera, Herrera and Smith 1992). Here a distinction is made between collective and dyadic representation (Weissberg 1978), the former referring to the relationship between the average citizen and the average representative and the latter referring to the relationship between individual representatives and their constituents. A third approach studies the relationship between party platforms and public opinion (for example, Monroe 1983).

5. Matsusaka and McCarty 2001 argue that initiatives may worsen congruence if legislators are uncertain of voters' preferences. Imagine, for example, that the gambling industry favors looser 
regulations and can place an initiative eliminating all regulations. Then if legislators do not know how voters would vote on such an initiative, they may favor loosening regulations to forestall the industry placing the initiative. This point applies with even greater force if money can induce voters to vote against their true interests.

6. Thus spending is the issue on which political cleavage takes place. Applying the model to the U.S., one can think of public spending as a measure of government size. Party A would then be the Democrats and Party B the Republicans. Our assumptions would then imply that all Republicans prefer smaller government, but might disagree on the regulatory issue. This does not seem unreasonable if we think of the regulatory issue being gun control, abortion, the death penalty, affirmative action, etc.

7. We assume that some voters are noise voters for two main reasons. First, noise voters make election outcomes stochastic and this significantly increases the range of parameter values for which (pure strategy) equilibria of our electoral competition game exist. Second, noise voters provide a simple way of modelling how campaign contributions can be used to increase a candidate's vote share.

8. The notation $-k$ refers to the opposite type to $k$. For example, $-k=r$ when $k=l$.

9. The assumption will definitely be satisfied if $\gamma^{l} \simeq \gamma^{r}$. For then $\psi\left(\gamma^{k}-\gamma^{-k}\right)$ is almost as big or bigger than $\psi\left(\gamma_{p}-\gamma_{a}\right)-\psi\left(\gamma^{k}-\gamma^{-k}\right)$ and, by assumption, $\Delta b(k)>\theta_{p}$.

10. The proof of this and subsequent results are available in an on-line Appendix.

11. Opinion polls suggest that the majority of the U.S. population opposes affirmative action and supports stronger immigration restrictions. However, candidates with stances along these lines are likely to lose the votes of minorities and immigrants.

12. Besley and Coate 2003a apply this idea to explain why electing and appointing regulators can make a difference to regulatory policy. When regulators are directly elected, then they are likely to be pro-consumer. However, when they are appointed they may be pro-industry because the regulator issue becomes bundled with other issues and is only salient for stakeholders in the industry.

13. Following the earlier logic, $\widehat{\psi}(\omega, z)=0$ if $\omega$ is less than $\frac{-(1-\mu)}{\mu}, \widehat{\psi}(\omega, z)=1$ if $\omega$ exceeds $\frac{1-\mu}{\mu}$ and $\widehat{\psi}(\omega, z)=1-H\left(\frac{-\mu \omega}{2(1-\mu)}+\frac{1}{2}, z\right)$ otherwise.

14. In the neo-Downsian models of Lindbeck and Weibull 1987, Dixit and Londregan 1996 and Grossman and Helpman 1996, parties just care about winning but inherit fixed positions on 
certain issues. If we were to assume that Party $A$ were constrained to choose a left-winger and Party $B$ a right-winger, then the single-issue voter and interest group influence arguments would be consistent with a Downsian objective.

15. Consider, for example, the case where regulation is not salient, and suppose that Party $A$ selected a type $(l, a)$ candidate and Party $B$ a type $(r, a)$. Then, one might argue that a type $(l, p)$ independent candidate would enter to compete with Party $A$ 's candidate. However, this argument neglects important issues inherent in elections with three or more candidates. If rational voters vote sincerely, entry by a type $(l, p)$ independent would simply split the left-wing vote and significantly enhance the probability of the right-wing candidate winning. If rational voters are strategic, left wingers will be reluctant to switch to the entrant for fear of wasting their vote. It follows that a type $(l, p)$ independent is likely either to increase the probability of the right wing candidate winning or to have no effect. Either way, such a candidate has little or no incentive to enter.

16. Thus, for both initiatives to appear on the ballot, there must be citizens whose gain from proposing each type of initiative exceeds $\delta$, given that the other initiative will be proposed. For neither initiative to be proposed, the gain for all citizens from proposing either initiative must be less than $\delta$ given that the other type of initiative will not be proposed. For only one type of initiative to be proposed, some citizen must gain more than $\delta$ from proposing the initiative and no other citizen can reap a benefit exceeding $\delta$ from proposing the other type of initiative.

17. Gerber 1999 and Matsusaka 2007 show how this can be done for discrete policy issues. For a continuous policy issue such as the minimum wage, one could ask respondents whether the current level was about right, too high, or too low. If the level were majority preferred, then the fractions answering too high and too low would perfectly offset each other. A measure of congruence would be the absolute value of the difference between the fractions responding too high and too low, with higher values of this statistic meaning less congruence. An improvement in congruence would mean a lower value of this statistic. Weissberg 1976 essentially uses this approach in his analysis of defense spending and foreign aid. Alternatively, if one could observe how a policy changed, one could simply ask people whether they approved of it. This is the approach used by Matsusaka 2004.

18. In practice, there is a negative correlation between the fraction of the electorate whose signatures are required and the probability that an initiative will be placed on the ballot (see 
Matsusaka 1995).

19. The fact that the cost of placing an initiative on the ballot is in terms of collecting supporting signatures, presumably reflects a desire to make $\delta$ higher for non-majoritarian initiatives. However, Broder 2000 argues that the cost of placing a non-majoritarian initiative is not significantly greater because of the ease of persuading people to sign petitions.

20. The normative case is expressed nicely by Teddy Roosevelt who reputedly said: "I believe in the Initiative and Referendum, which should be used not to destroy representative government, but to correct it whenever it becomes misrepresentative." (Cited on the website of the Initiative and Referendum Institute http://www.iandrinstitute.org.) 